\title{
Perturbation Analysis for Periodic Heat Transfer in Radiating Fins
}

\author{
A. A.ziz, Riyadh, Saudi Arabia and T.Y. Na, Dearborn, Michigan, USA
}

Abstract. A perturbation analysis is presented for periodic heat transfer in radiating fins of uniform thickness. The base temperature is assumed to oscillate around a mean value. The perturbation expansion is carried out in terms of dimensionless amplitude $\varepsilon$ of the base temperature oscillation. The zero-order problem which is nonlinear, and corresponds to the steady state fin behaviour, is solved by quasilinearization. A method of complex combination is used to reduce both the first and the second order problems to two, coupled linear boundary value problems which are subsequently solved by a noniterative numerical scheme. The second-order term is composed of an oscillatory component with twice the frequency of base temperature oscillation and a time-independent term which causes a net change in the steady state values of temperature and heat transfer rate. Within the range of parameters used, the net effect is to decrease the mean temperature and increase the mean heat transfer rate. This is in constrast to the linear case of convecting fins where the mean values are unaffected by base temperature oscillations. Detailed numerical results are presented illustrating the effects of fin parameter $N$ and dimensionless frequency $B$ on temperature distribution, heat transfer rate, and time-average fin efficiency. The time-average fin efficiency is found to reduce significantly at low $\mathrm{N}$ and high $\mathrm{B}$.

\section{Störungsanalyse für periodische Wärmeübertragung an Strahlungsrippen}

Zusammenfassung. Eine Störungsanalyse wird für periodische Wärmeübertragung in Strahlungsrippen gleicher Dicke vorgelegt. Die Fußtemperatur wird als um einen Mittelwert schwingend angenommen. Die Störungsentwicklung wird in Termen einer dimensionslosen Amplitude $\varepsilon$ dieser Schwingung angesetzt. Das Problem nullter Ordnung, das nichtlinear ist und dem stationären Verhalten der Rippe entspricht, wird durch Quasilinearisierung gelöst. Eine Methode der komplexen Kombination wird angewandt, um die Probleme erster und zweiter Ordnung auf zwei gekoppelte Grenzwertprobleme zu reduzieren, die nacheinander nach einem nichtiterativen Schema gelöst werden. Der Term zweiter Ordnung besteht aus einer Schwingungskomponente mit der doppelten Frequenz der Schwingung der Fußtemperatur und einem zeitunabhängigen Term, der eine Nettoänderung der stationären Werte der Temperatur und der Wärmeübertragung verursacht. Im verwendeten Bereich der Parameter tritt eine Abnahme der mittleren Temperatur und eine Zunahme der mittleren Wärmeübertragung auf. Das steht im Gegensatz zum linearen Fall der Konvektionsrippe, bei dem die Mittelwerte durch Schwingungen der Fußtemperatur nicht beeinflußt werden. Detaillierte numerische Ergebnisse zeigen die Einfliusse des Rippenparameters $N$ und der dimensionslosen Frequenz $B$ auf Temperaturverteilung, Wärmeübertragung und zeitliches Mittel des Rippengütegrades. Dieses zeitliche Mittel nimmt merklich ab bei kleinem $\mathrm{N}$ und hohem $\mathrm{B}$.

Nomenclature

$b$
$B$
$E$
$f_{0}, f_{1}$
$g_{0}, g_{1}, g_{2}$
$h_{0}, h_{1}, h_{2}$
$k$
$L$
$N$
$q$
$Q$
$t$
$T$
$T_{b}$
$T_{S}$

fin thickness

dimensionless frequency, $\omega L^{2} / \alpha$

emissivity

functions of $X$

functions of $X$

functions of $X$

thermal conductivity

fin Length

heat transfer rate

dimensionless heat transfer rate, $\mathrm{qL} / \mathrm{kbT}_{\mathrm{bm}}$

time

temperature

fin base temperature

effective sink temperature

${ }_{b \mathrm{bm}}$
$\mathrm{x}$
$X$
$\varepsilon$
$\alpha$
$\eta$
$\bar{\eta}$
$\eta_{\mathrm{ss}}$
$\theta^{\mathrm{g}}$
$\theta_{0}$
$\theta_{1}$
$\theta_{2}$
$\theta_{2 \mathrm{~s}}$
$\lambda_{,}, \lambda_{1}, \lambda_{2}$
$\Phi$
$\Phi_{1}$

mean fin base temperature

axial distance

dimensionless axial distance, $x / L$ dimensionless amplitude of base temperature (s.Eq.2)

thermal diffusivity

instantaneous fin efficiency

time-average fin efficiency

steady state fin efficiency

dimensionless temperature, $\mathrm{T} / \mathrm{T}_{\mathrm{bm}}$

zero-order approximation

first-order approximation

second-order approximation

steady component of $\theta_{2}$

constants

complex function of $\mathrm{X}$

real part of $\Phi$ 


$\begin{array}{ll}\Phi_{2} & \text { imaginary part of } \Phi \\ \Psi & \text { complex function of } \mathrm{X} \\ \Psi_{1} & \text { real part of } \Psi\end{array}$

\section{Introduction}

Extended surfaces (or fins) used on electronic components, solar collectors, internal combustion engines etc. often operate under periodic thermal conditions. Under these circumstances, it is important to assess how the actual performance could deviate from the usual steady-state behaviour. The earliest analytical studies in this area considered purely convecting fins of uniform thickness. For example, Yang [1] studied a straight fin with oscillating base temperature and obtained a closed form solution using the method of complex combination. This was subsequently extended to an annular fin by Aziz [2]. A similar analysis for the case of oscillating environment temperature has been carried out recently [3]. Other periodic conditions such as oscillating base heat flux or convective heating of the fin by an oscillating temperature fluid have been analyzed by Suryanarayana [4] using Laplace transform. A more recent study by Aziz and $\mathrm{Na}$ [5] considered a convecting fin of arbitrary profile with either the base temperature or environment temperature oscillating with time. The solution was achieved by using method of complex combination in conjunction with a numerical scheme. The most important conclusion which emerged from the aforementioned studies was that for fin parameter $N$ is less than 1 , the time-average fin efficiency over a cycle is reduced with the increase in the amplitude and frequency of oscillation.

As an extension to convecting fin studies, more recent effort has been directed to radiating or combined radiating-convecting fins. The paper by Eslinger and Chung [6] uses a finite element approach to analyze a straight fin with simultaneous convection and radiation and oscillating base temperature. A.lthough the formulation incorporated refinements such as fin-to-base and fin-to-fin radiation interactions, the program execution required long time. A. related study applicable to a single fin of annular geometry has been reported by Campo [7]. His approach was to discretize the position variable and thus generate

$\begin{array}{ll}\Psi_{2} & \text { imaginary part of } \Psi \\ 5 & \text { dimensionless time, } \alpha t / L^{2} \\ \omega & \text { frequency of base temperature oscilla- } \\ & \text { tion }\end{array}$

a system of nonlinear ordinary differential equations in time. These were ultimately integrated with RungeKutta iterative scheme.

In the present paper, we present a semi-numerical approach to solve for steady periodic heat transfer in a radiating fin with oscillating base temperature. The dimensionless amplitude of the base temperature is chosen as a perturbation parameter $\varepsilon$ and the temperature is expressed as a series in $\varepsilon$. The zero-order problem then corresponds to the known steady-state behaviour. The first and the second order problems constitute two linear partial differential equations. Using the method of complex combination, each of them can be reduced to two, coupled linear boundary values which are finally integrated numerically by a noniterative procedure. The approach offers two distinct advantages. First, it reveals some interesting features associated with the nonlinear radiation which tend to remain obscure with the direct numerical schemes such as in $[6,7]$. Second, the computation is indeed very fast. A.ll the data presented were generated within CPU time of 15 seconds on Amdahl $470 \mathrm{~V} / 7$ system of the University of Michigan.

\section{Problem Formulation}

Consider a straight fin of uniform thickness $b$ and length $L$ with its base temperature varying periodically as shown in Fig.1. The fin surface radiates to an environment with zero effective sink temperature. Other usual assumptions involved in the analysis are: 1) conduction is one-dimensional, 2) the fin tip is insulated, 3) there is no fin-to-base radiative interaction and 4) all thermal properties are constant. This simple model is chosen because the purpose is to demonstrate how to handle the radiation nonlinearity. However, the analysis can be readily generalized to accomodate surface convection and nonzero sink temperature and different fin configurations with some additional algebraic manipulation. 
Based on the above, the fin equation and boundary conditions in dimensionless form can be written as

$\frac{\partial^{2} \theta}{\partial X^{2}}-N \theta^{4}=\frac{\partial \theta}{\theta \zeta}$

$X=0, \theta=1+\varepsilon \cos B \zeta ; X=1, \frac{\partial \theta}{\partial X}=0$

where the symbols are as defined in the nomenclature.

\section{Solution Method}

Since the dimensionless amplitude parameter $\varepsilon$ would in practice remain below unity (Fig.1) we assume a regular perturbation expansion for $\theta$ in terms of $\varepsilon$ as

$\theta(X, \zeta)=\theta_{0}(X)+\varepsilon \theta_{1}(X, \zeta)+\varepsilon^{2} \theta_{2}(X, \zeta)+\cdots$

Substituting (3) into Eqs. $(1,2)$ and equating the coefficients of like powers of $\varepsilon$ on both sides of Eqs. (1, 2) we have

$\varepsilon^{0}: \theta_{0}^{\prime \prime}-N \theta_{0}^{4}=0$

$X=0, \quad \theta_{0}=1 ; \quad x=1, \quad \theta_{0}^{1}=0$

where primes in Eqs. $(4,5)$ and in all subsequent equations denote total differentiation with respect to $\mathrm{X}$.

$\varepsilon^{1}: \frac{\partial^{2} \theta_{1}}{\partial x^{2}}-4 N \theta_{0}^{3} \theta_{1}=\frac{\partial \theta_{1}}{\partial \zeta}$

$X=0, \quad \theta_{1}=\cos B \zeta ; \quad x=1, \quad \frac{\partial \theta_{1}}{\partial x}=0$

$\varepsilon^{2}: \frac{\partial^{2} \theta_{2}}{\partial \mathrm{X}^{2}}-4 \mathrm{~N} \theta_{0}^{3} \theta_{2}-6 \mathrm{~N} \theta_{0}^{2} \theta_{1}^{2}=\frac{\partial \theta_{2}}{\partial \zeta}$

$X=0, \quad \theta=0 ; \quad X=1, \quad \frac{\partial \theta}{\partial X}=0$

Higher-order equations can be written in a similar manner. However, we truncate the expansion at the third term because this would be found sufficiently accurate upto $\varepsilon=0.4$ which means a maximum of 40 per cent deviation of base temperature from its mean value. In most practical situations, deviations

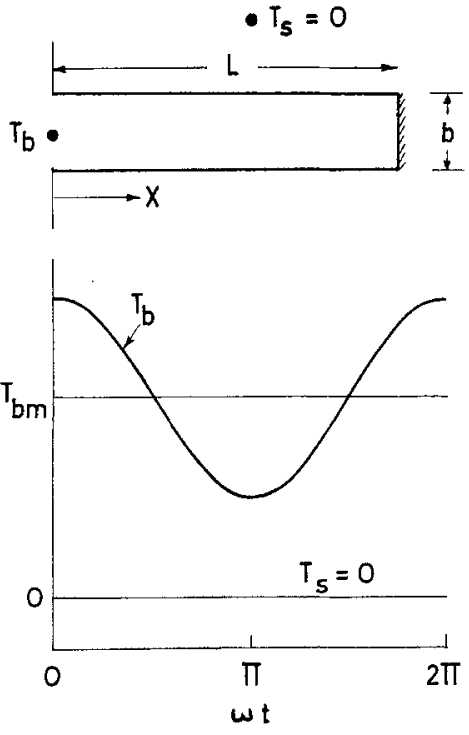

Fig.1. Fin geometry and base temperature oscillation

would fall within this limit. Indeed, in previous studies $[1,6]$ the maximum value assigned to $\varepsilon$ was 0.2 . The zero-order problem corresponds to the steadystate condition and its solution is known, both in exact but implicit form and in numerical form $[8,9]$. However, we had to generate our own numerical solution for use in the subsequent solutions of first and second order equations. This was obtained by using quasilinearization in conjunction with the method of superposition as described later.

To solve Eqs. $(6,7)$ we follow the method of complex combination and assume the solution of the form

$\theta_{1}(X, \zeta)=R[\Phi(X) \exp (i B \zeta)]$

where $R[$ [ represents the real part of the quantity in brackets. Using $(10)$ in Eqs. $(6,7)$ the equation for $\Phi$ becomes

$\Phi^{\prime \prime}-\left(4 N \theta_{0}^{3}+i B\right) \Phi=0$

$X=0, \Phi=1 ; X=1, \Phi^{\prime}=0$.

Letting

$\Phi=\Phi_{1}+\mathrm{i}_{2}$

equations for $\Phi_{1}$ and $\Phi_{2}$ now constitute two coupled, linear boundary value problems as follows 
$\Phi_{1}^{\prime \prime}-4 N \theta_{0}^{3} \Phi_{1}+B \Phi_{2}=0$

$X=0, \Phi_{1}=1 ; X=1, \quad \Phi_{1}^{\prime}=0$

and

$\Phi_{2}^{\prime \prime}-4 N \theta_{0}^{3} \Phi_{2}-B \Phi_{1}=0$

$X=0, \Phi_{2}=0 ; X=1, \Phi_{2}^{\prime}=0$.

The solution of Eqs. (14)-(17) by a noniterative numerical scheme will be discussed later.

Coming to the solution of Eqs. $(8,9)$ we note that $\theta_{1}^{2}$ is associated with one of the terms of Eq. (8). Using Eq. (10) it can be shown that

$\theta_{1}^{2}=\frac{1}{2}\left(\Phi_{1}^{2}+\Phi_{2}^{2}\right)+\frac{1}{2} R\left[\Phi^{2} \exp (i 2 B \zeta)\right]$.

This suggests that the solution for $\theta_{2}$ must be expressed as the sum of a steady component $\theta_{2 s}$ and an oscillatory component of frequency $2 \mathrm{~B}$. Thus, we write

$\theta_{2}(X, \zeta)=\theta_{2 s}+R[\Psi(X) \exp (i 2 B \zeta)]$

Substituting (19) into Eqs. (8,9) the equations governing $\theta_{2 s}$ and $\psi$ are obtained as

$\theta_{2 s}^{\prime \prime}-4 N \theta_{0}^{3} \theta_{2 s}-3 N \theta_{0}^{2}\left(\Phi_{1}^{2}+\Phi_{2}^{2}\right)=0$

$X=0, \quad \theta_{2 s}=0 ; X=1, \quad \theta_{2 s}^{\prime}=0$

$\Psi \prime \prime-\left(4 N \theta_{0}^{3}+2 \mathrm{iB}\right) \Psi-3 N \theta_{0}^{2} \Phi^{2}=0$

$X=0, \quad \Psi=0 ; \quad X=1, \quad \Psi 1=0$.

By letting

$\Psi=\Psi_{1}+i \Psi_{2}$

two coupled, linear boundary value problems for $\Psi_{1}$ and $\Psi_{2}$ appear as

$\Psi_{1}^{\prime \prime}-4 \mathrm{~N} \theta_{0}^{3} \Psi_{1}+2 \mathrm{~B} \Psi_{2}-3 \mathrm{~N} \theta_{0}^{2}\left(\Phi_{1}^{2}-\Phi_{2}^{2}\right)=0$

$\mathrm{X}=0, \quad \Psi_{1}=0 ; \quad \mathrm{X}=1, \quad \Psi_{1}^{1}=0$

$\Psi_{2}^{\prime \prime}-4 \mathrm{~N} \theta_{0}^{3} \Psi_{2}-2 \mathrm{~B} \Psi_{1}-6 \mathrm{~N} \theta_{0}^{2} \Phi_{1} \Phi_{2}=0$
$\mathrm{X}=0, \quad \Psi_{2}=0 ; \mathrm{X}=1, \Psi_{2}^{\prime}=0$.

The numerical solutions of Eqs. $(20,21)$ and Eqs. (25) $-(28)$ are discussed in the following section.

\section{Numerical Schemes}

Consider the solution of Eqs. $(4,5)$. Using quasilinearization [10] Eq. (4) can be approximated as

$\theta_{0}^{(\gamma+1)^{\prime \prime}}-4 N \theta_{0}^{(\gamma)^{3}} \theta_{0}^{\gamma+1}=-3 N \theta_{0}^{(\gamma)^{4}}$

where " $g$ " refers to the number of iteration. By assuming the first approximation as

$\theta_{0}^{(1)}=1$

successive approximations can be found by solving Eq. (29) subject to the following boundary conditions (which follow from Eq. (5))

$X=0, \quad \theta^{(\gamma+1)}=1, \quad X=1, \quad \theta_{0}^{(\gamma+1)^{\prime}}=0$

Since there is only one missing derivative at $\mathrm{X}=0$, i.e. $\theta_{0}^{(\gamma+1)^{\prime}}$ the solution is assumed as

$\theta_{0}^{(\gamma+1)}=f_{0}+\lambda f_{1}$

where $\lambda$ is the missing derative $\theta_{0}^{(\gamma+1)^{\prime}}$ at $X=0$. Using (32) in (29) and (31) gives the following initial value problems for $f_{0}$ and $f_{1}$

$f_{0}^{\prime \prime}-4 N \theta_{0}^{(\gamma)^{3}} f_{0}=-3 N \theta_{0}^{(\gamma)^{4}}$

$\mathrm{X}=0, \mathrm{f}_{0}=1, \quad \mathrm{f}_{0}^{\prime}=0$

and

$f_{1}^{\prime \prime}-4 N \theta_{0}^{(\gamma)^{3}} f_{1}=0$

$X=0, \quad f_{1}=0, \quad f_{1}^{\prime}=1$.

Equations (33-36) are now integrated without iteration using a fourth-order Runge-Kutta scheme. To find $\lambda$, we use the terminal values of derivatives, i.e. $f_{0}^{\prime}(1)$ and $f_{1}^{\prime}(1)$ and invoke the boundary condition (31) at $X=1$ to obtain 
$f_{0}^{\prime}(1)+\lambda f_{1}^{\prime}(1)=0$

from which

$\lambda=-f_{0}^{\prime}(1) / f_{1}^{\prime}(1)$.

Using the solution for $\mathrm{f}_{0}$ and $\mathrm{f}_{1}$ and $\lambda$ in (32) gives the second approximation for $\theta_{0}^{1}(2)$. The procedure is repeated until the solution converges. In all the calculations performed, convergence was achieved with very few iterations.

Next we consider the solution of Eqs.(14-17). Since there are two missing initial derivatives at $\mathrm{X}=0$, i.e. $\Phi_{1}^{\prime}$ and $\Phi_{2}$, the solutions are assumed as [10]

$\Phi_{1}=g_{0}+\lambda_{1} g_{1}+\lambda_{2} g_{2}$

$\Phi_{2}=h_{0}+\lambda_{1} h_{1}+\lambda_{2} h_{2}$

where $\lambda_{1}$ and $\lambda_{2}$ are the missing derivatives $\Phi_{1}^{\prime}(0)$ and $\Phi_{2}^{\prime}(0)$ respectively. Using (39) and (40) in Eqs. (14-17) gives the following initial value problems for $g_{0}, g_{1}, g_{2}, h_{0}, h_{1}$ and $h_{2}$

$\mathrm{g}_{0}^{\prime \prime}-4 \mathrm{~N} \theta_{0}^{3} \mathrm{~g}_{0}+\mathrm{Bh} \mathrm{H}_{0}=0$

$h_{0}^{\prime \prime}-4 N \theta_{0}^{3} h_{0}-B g_{0}=0$

$g_{1}^{\prime \prime}-4 N \theta_{0}^{3} g_{1}+B h_{1}=0$

$h_{1}^{\prime \prime}-4 N \theta_{0}^{3} h_{1}-B g_{1}=0$

$g_{2}^{\prime \prime}-4 N \theta_{0}^{3} g_{2}+B h_{2}=0$

$h_{2}^{\prime \prime}-4 N \theta_{0}^{3} h_{2}-B g_{2}=0$

with the initial conditions

$$
\begin{aligned}
& \mathrm{X}=0, \mathrm{~g}_{0}=1, \mathrm{~g}_{1}=\mathrm{g}_{2}=0, \mathrm{~h}_{0}=\mathrm{h}_{1}=\mathrm{h}_{2}=0 \\
& \mathrm{X}=0, \mathrm{~g}_{0}^{\prime}=0, \mathrm{~g}_{1}^{\prime}=1, \mathrm{~g}_{2}^{\prime}=0, \mathrm{~h}_{0}^{\prime}=0, \mathrm{~h}_{1}^{\prime}=0, \mathrm{~h}_{2}^{\prime}=1 .
\end{aligned}
$$

Using a fourth-order Runge-Kutta scheme Eqs. (4148) are integrated without iteration. To find $\lambda_{1}$ and $\lambda_{2}$ we use the terminal values of derivatives i.e. $g_{0}^{\prime}(1), g_{1}^{\prime}(1), g_{2}^{\prime}(1), h_{0}^{\prime}(1), h_{1}^{\prime}(1)$ and $h_{2}^{\prime}(1)$ in boundary conditions at $\mathrm{X}=1$ in Eqs. $(15,17)$ to give

$g_{0}^{\prime}(1)+\lambda_{1} g_{1}^{\prime}(1)+\lambda_{2} g_{2}^{\prime}(1)=0$

and

$h_{0}^{\prime}(1)+\lambda_{1} h_{1}^{\prime}(1)+\lambda_{2} h_{2}^{\prime}(1)=0$.

Solving $(49,50)$ simultaneously, we get

$\lambda_{1}=\frac{h_{0}^{\prime}(1) g_{2}^{\prime}(1)-g_{0}^{\prime}(1) h_{2}^{\prime}(1)}{h_{2}^{\prime}(1) g_{1}^{\prime}(1)-g_{2}^{\prime}(1) h_{1}^{\prime}(1)}$

and

$\lambda_{2}=\frac{h_{1}^{\prime}(1) g_{0}^{\prime}(1)-g_{1}^{\prime}(1) h_{0}^{\prime}(1)}{h_{2}^{\prime}(1) g_{1}^{\prime}(1)-g_{2}^{\prime}(1) h_{1}^{\prime}(1)}$.

The solutions for $\Phi_{1}$ and $\Phi_{2}$ are thus completely determined.

Turning to the solution of Eqs. $(20,21)$, since there is one missing derivative at $\mathrm{X}=0 \mathrm{i} . e . \theta_{2 \mathrm{~S}}(0)$ we follow exactly the same procedure as detailed previously Eqs. (32-38) except that no iteration would be needed in this case. Finally considering the solution of Eqs. (25-28), there are two missing derivatives at $X=0, i . e . \Psi_{1}^{\prime}(0)$ and $\Psi_{2}^{\prime}(0)$ and therefore the same procedure as detailed by Eqs. $(39-52)$ is applicable.

It should be emphasized that all computations except for $\theta_{0}$ are carried out noniteratively.

\section{Results and Discussion}

A sample solution for $\theta_{0}, \theta_{2 s}, \Phi_{1}, \Phi_{2}, \Psi_{1}$ and $\Psi_{2}$ is shown in Fig.2. Using Eqs. (10, 19) in Eq. (3) the solution for the temperature distribution in terms of quantities determined is

$$
\begin{aligned}
\theta=\theta_{0} & +\varepsilon^{2} \theta_{2 s}+\varepsilon\left(\Phi_{1} \cos B \zeta-\Phi_{2} \sin B \zeta\right) \\
& +\varepsilon^{2}\left(\Psi_{1} \cos 2 B \zeta-\Psi_{2} \sin 2 B \zeta\right)+o\left(\varepsilon^{3}\right) .
\end{aligned}
$$

The instantaneous heat transfer rate can now be evaluated in terms of the temperature gradient at the base $(\mathrm{X}=0)$. In dimensionless form it is 


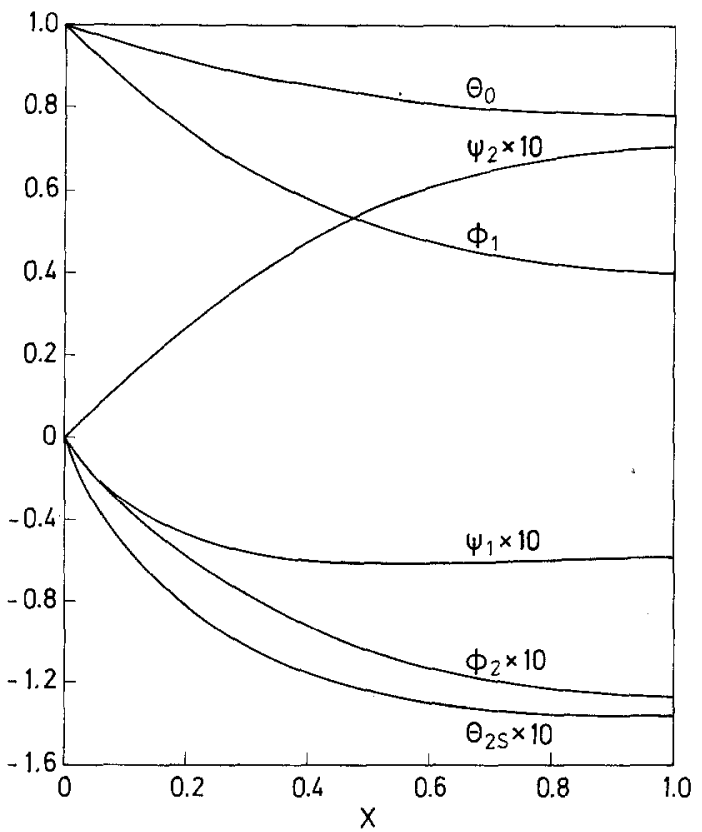

Fig.2. Sample solutions for $\theta_{0}, \theta_{2 s}, \Phi_{1}, \Phi_{2}, \Psi_{1}$ and $\Psi_{z} ; N=1, B=1$

$$
\begin{aligned}
-Q & =\theta_{0}^{\prime}(0)+\varepsilon^{2} \theta_{2 S}^{\prime}(0)+\varepsilon\left[\Phi_{1}^{\prime}(0) \cos B \zeta-\Phi_{2}^{\prime}(0) \sin B \zeta\right] \\
& +\varepsilon^{2}\left[\Psi_{1}^{\prime}(0) \cos 2 B \zeta-\Psi_{2}^{\prime}(0) \sin 2 B \zeta\right]+0\left(\varepsilon^{3}\right) .
\end{aligned}
$$

The instantaneous fin efficiency $\eta$ follows as

$$
\eta=\frac{Q}{N(1+\varepsilon \cos B \zeta)^{4}} \text {. }
$$

The time-average fin efficiency $\bar{\eta}$ over a cycle can be obtained as

$\bar{\eta}=\frac{1}{2 \pi N} \int_{0}^{2 \pi} \frac{Q}{(1+\varepsilon \cos B \zeta)^{4}} d(B \zeta)$.

\section{Temperature Distribution}

The perturbation solution for $\theta, \mathrm{Eq} .(53)$ shows that the second-order term has a steady component $\theta_{2 \mathrm{~s}}$ which causes a net change in the steady state value $\theta_{0}$ in the absence of oscillation. For all parametric values of $N$ and $B$ used in the computations, $\theta_{2 s}$ at all axial locations is always negative (Fig. 2 for example) there is a reduction in the mean temperature throughout the fin. This is a consequence of the nonlinear radiative cooling mechanism and is in contrast

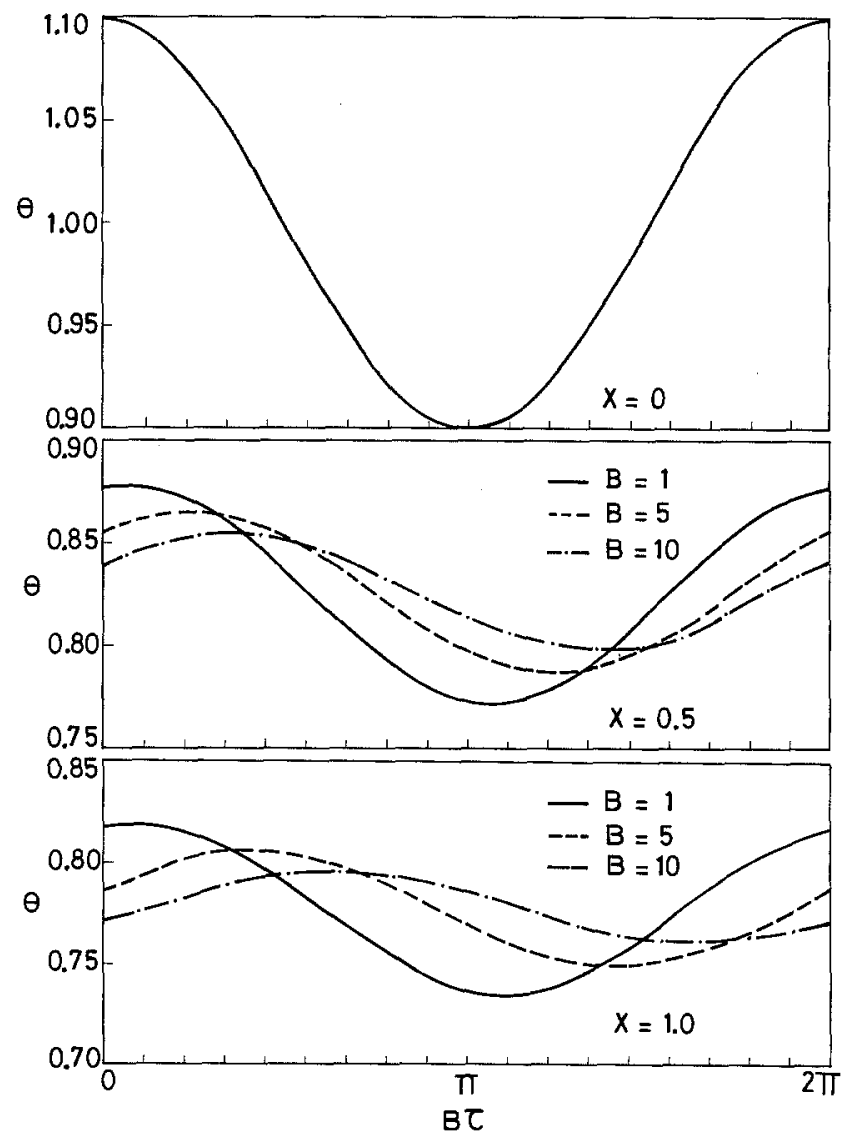

Fig.3. Effect of parameter $B$ on temperature distribution; $N=1, \varepsilon=0.1$

to the linear case of convecting fin where the mean values remain and unaffected by base temperature oscillation. However, the reduction in mean temperature is small because $\theta_{2 s}$ was invariably an order of magnitude less than $\theta_{0}$ ( $F i g .2$ for example).

Another noteworthy feature of the solution is the presence of a second-order oscillatory component with twice the frequency of base temperature oscillation. This again is related to the nonlinearity of the problem and is absent in the linear case of the convecting fin $[1]$.

To demonstrate the effects of the frequency parameter $\mathrm{B}$ on temperature distribution, a typical set of results is plotted in Fig. 3 for $N=1$ and $\varepsilon=0.1$. The value of $\mathrm{N}$ chosen is representative of the values encountered in practice [9]. The amplitude of oscillation is seen to decrease significantly as one proceeds from the base $(X=0)$ to the tip $(X=1)$ while the phase angle increases. At any axial location, the effect of increasing the frequency is to reduce the 

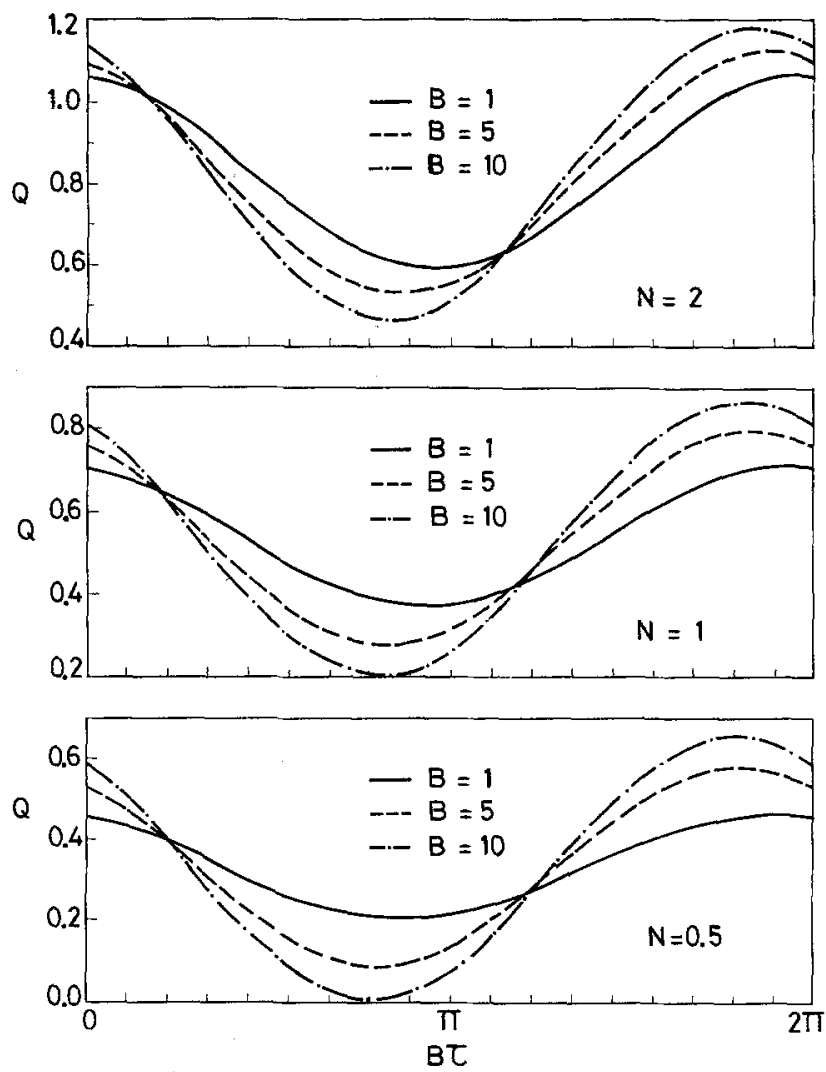

Fig. 4. Effect of parameters $B$ and $N$ on istantaneous heat transfer rate; $\varepsilon=0.1$

amplitude but increase the phase angle. The same pattern also exists in the case of convecting fin [1].

\section{Heat Transfer Rate}

Examining $\mathrm{Eq}(54)$ it is seen that the presence of the term $\varepsilon^{2} \theta_{2 s}^{\prime}(0)$ changes the steady heat transfer rate which, in the absence of oscillation, is given by $\theta_{0}^{\prime}(0)$. Since $\theta_{2 s}^{i}(0)$ turned out to be negative for all values of $B$ and $N$ used (see Fig. 2 for example) it implies an increase in the mean heat transfer rate. Contrary to its small effect on mean temperature, the effect of oscillation on mean heat transfer rate is significant because the magnitudes of $\theta_{0}^{\prime}(0)$ and $\theta_{2 s}(0)$ are comparable. For example, with $\mathrm{N}=1, \mathrm{~B}=1$ and $\varepsilon=0.2$, the increase in mean heat transfer rate is about 6 per cent.

Figure 4 shows how the instantaneous heat transfer rate is influenced by parameters $B$ and $N$ with $\varepsilon$ fixed at 0.1 . At a given $B$, the amplitude of oscillation increases as $\mathrm{N}$ increases. This effect is most
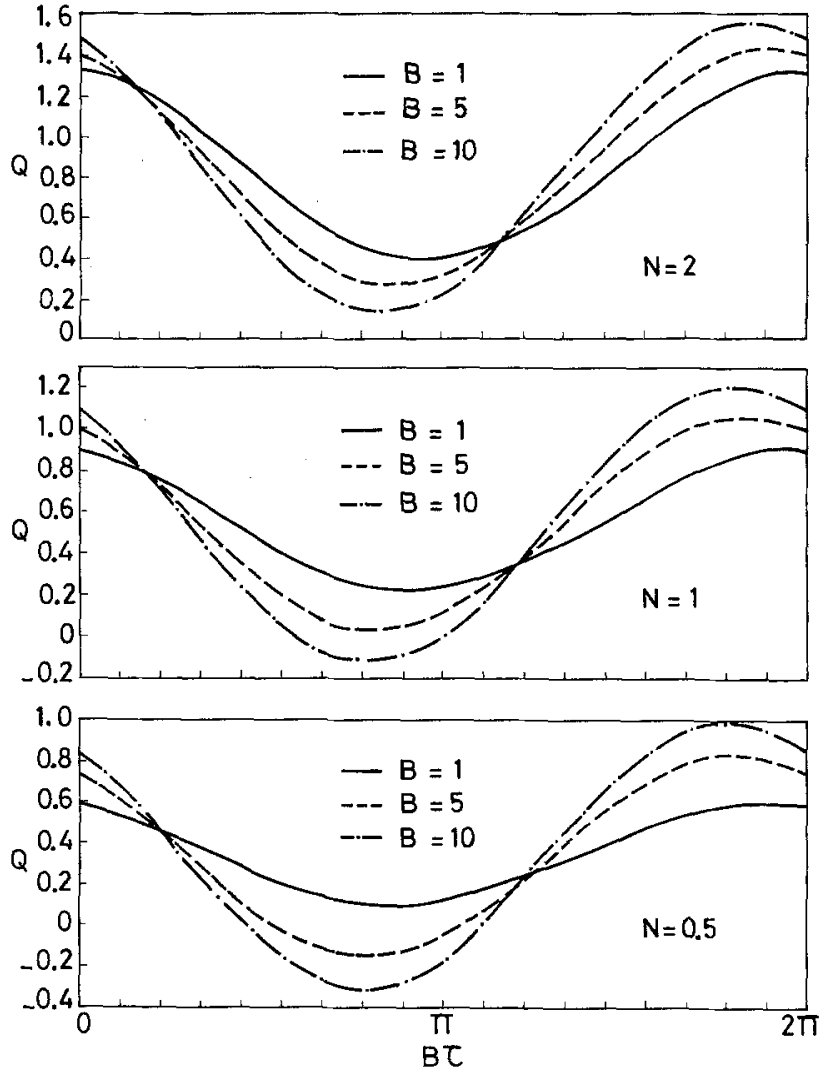

Fig.5. Effect of parameters $\mathrm{B}$ and $\mathrm{N}$ on instantaneous heat transfer rate, $\varepsilon=0.2$

pronounced at $B=1$. For a given $N$, the increase in $B$ causes both the amplitude and phase angle to increase. In contrast to the temperature (at any axial location) which lags behind the base temperature (Fig. $3)$, the heat transfer rate always leads the base temperature (Fig.4).

As the amplitude $\varepsilon$ of the base temperature oscillation increases, the instantaneous heat transfer curves exhibit an interesting feature as shown in Fig.5 which corresponds to $\varepsilon=0.2$. At $N=2$, the heat transfer is positive throughout the cycle for all three values of $\mathrm{B}$. However, as $\mathrm{N}$ is reduced to unity, the heat transfer becomes negative for part of cycle for $B=10$. With $N$ reduced to 0.5 , the negative heat flow is further increased and occurs even at $B=5$. This negative heat flow means that the heat actually flows back into the fin base instead of flowing out. The phenomenon of back heat flow at low $\mathrm{N}$ and high $B$ has also been noted in convecting fin studies $[1,2]$ and obviously results in deterioration in the overall heat transfer capability of the fin. 

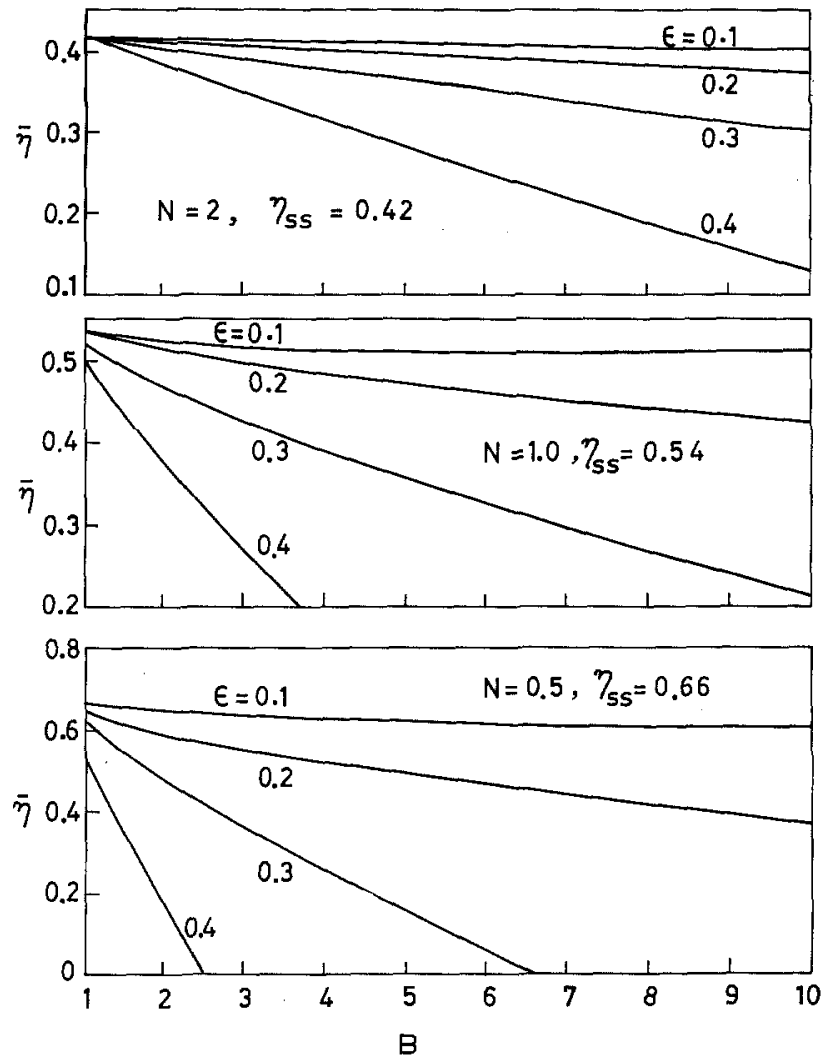

Fig.6. Effect of parameters $B, N$ and $\varepsilon$ on timeaverage fin efficiency

\section{Fin Efficiency}

The time-average fin efficiency calculated using $\mathrm{Eq}$. (56) has been plotted in Fig. 6 for a range of parameters involved. The steady state fin efficiency for constant base temperature, denoted by $\eta_{\mathrm{Ss}}$, is given to indicate the extent of departure of the time-average fin efficiency. With $\varepsilon=0.1$ which means a ten per cent deviation of base temperature from its mean value, the time-average efficiency is practically unaffected at low values of $B$ but gradually deminishes as $\mathrm{B}$ increases. For example with $\mathrm{N}=0.5$, the reduction at $B=10$ is about 12 per cent compared to $\eta_{s s}$. As $\varepsilon$ increases further it brings about drastic reduction in time-average efficiency particularly at low $\mathrm{N}$ and high $\mathrm{B}$.

The results for $\mathrm{N}=0.5$ and 1.0 are of immediate practical significance because they encompass the region of optimum dimensioned radiating fin of rectangular profile, i.e. $N=0.8045[8]$. Therefore, for an optimum radiating fin the base temperature oscillations can prove quite detrimental to its overall performance. With purely convecting fins of rectangular shape, on the other hand, the time-average efficiency is significantly reduced only for $N$ (as defined in [1]) below unity and since the optimum value of $\mathrm{N}$ is 1.4192, the performance of an optimum convecting fin is not likely to be affected significantly as a result of base temperature oscillation. It must, however be emphasized that the foregoing conclusions are valid within the ranges of parameters used in the present study.

A final remark may be made concerning the accuracy of the perturbation solution. At $\varepsilon=0.3$ and 0.4 , the accuracy may seem questionable. However, a similar analysis for a convecting fin shows that the two-term perturbation solution (the rest of the terms being identically zero) reproduces the exact solution available in [1]. This clearly shows that the perturbation solution should be quite accurate even at $\varepsilon=0.4$. The exact solution also provided a check on the validity and accuracy of the numerical scheme used.

\section{A.cknowledgement}

The first author is grateful to his wife and children who allowed him to spend the summer of 1980 away from them, to carry out this work.

\section{References}

1. Yang, J.W.: Periodic Heat Transfer in Straight Fins. Journal of Heat Transfer 94 (1972) 310-314

2. Aziz, A.: Periodic Heat Transfer in Annular Fins. Journal of Heat Transfer 97 (1975) 302-303

3. Aziz, A.; Sofrata, H.: Fin Performance in Oscillating Temperature Environment. Applied Energy (in press)

4. Suryanarayana, N.V.: Transient Response of Straight Fins. Journal of Heat Transfer 97 (1975) 417-423

5. Aziz, A.; Na, T.Y.: Steady Periodic Heat Transfer in Fins of Arbitrary Profile. Numerical Heat Transfer 3 (1980)

6. Eslinger, R.G.; Chung, B.T.F.: Periodic Heat Transfer in Radiating and Convecting Fins or Fin Arrays. AIAA Journal 17 (1979) 1134-1140

7. Campo, A.: Unsteady Heat Transfer from a Circular Fin with Nonlinear Dissipation. Wärmeund Stoffubertragung 10 (1977) 203-210

8. Qern, D.Q.; Kraus, A.D.: Extended Surface Heat Transfer. McGraw-Hill, N.Y. (1972) 
9. Sparrow, E.M.; Niewerth, E.R.: Radiating, Convecting and Conducting Fins: Numerical and Linearized Solutions. Int. J. Heat \& Mass Transfer 11 (1968) 377-379

10. Na, T.Y.: Computation Methods in Engineering Boundary Value Problems. Academic Press, N.Y. (1979)

Received October 13, 1980
Professor A. A.ziz

Department of Mechanical Engineering

College of Engineering

P.O. Box 800

Riyadh, Saudi Arabia

Professor T.Y. Na

Department of Mechanical Engineering University of Michigan-Dearborn

Dearborn, Michigan, USA 